\title{
Households Willingness to Pay for Improved Water Services: The Case of Burayu Town Administration: Application of Contingent Valuation Method
}

\author{
Beyene Ibsa \\ School of Business and Economics, Oromia State University, P.O.Box 209, Batu, Ethiopia
}

\begin{abstract}
This study is initiated by the current deep rooted problem of improved water supply prevailing in Burayu town and its primary objective is to estimate mean willingness to pay of households using contingent valuation method. A total of 239 sampled households are interviewed in person. A single bounded closed ended followed by open-ended format were used to elicit willingness to pay for improved water. Of 217 respondents $160(73.3 \%)$ accepted bid values of improved water provided to them. The data was analyzed both in descriptive and econometric models. The probit and tobit models were used for empirical analyses. In closed ended format, the households' mean willingness to pay for one Jeri can of improved water was 31.5 cents and 42.7 cents in open ended format. Households characteristics' such as age, income, occupation and education are positively determine the probability of accepting the given bid value of improved water. The bid value, dummy variables such as source of water, quantity and quality negatively affect the willingness to pay for improved water in probit model. Those variables affecting the likely of willingness to pay positively also have the same sign in tobit model of determining the maximum willingness to pay. The aggregate willingness to pay of households was estimated to be 1613942.62 birr per month. The current average revenue of the town's water supply and sewerage enterprise is estimated to 515009.95 birr for one per month. The study revealed that households are willing to pay more of the current tariff blocks for improvement. Therefore if the improvement scenario comes to effect in one way it solves the shortage of improved water problems in the other way the town's water supply and sewerage enterprise can collect more revenue from service charges.
\end{abstract}

Keywords: Willingness to pay, Contingent valuation, Use value and Non-use value.

DOI: $10.7176 / \mathrm{JESD} / 11-3-01$

Publication date: February $29^{\text {th }} 2020$

\subsection{INTRODUCTION}

The past history shows that water was considered as free good because of its abundance in supply. Overtime with the increasing number of global population and expansion of human economic activities the surface as well as ground water becomes contaminated and resulted in shortages of safe water for human consumption. Due to these facts the scarcity of improved water becomes the primary concern of governments and the traditional thinking of water as free good is changed to consider water as economic good. Water is an environmental resource which has no actual market price. One of the problems with environmental goods of public good nature is that they are the source of market failure. Measuring the values of environmental goods and services is important to ease the allocation process. Allocation of public goods requires huge financial expenditures which sometimes above the funding capacity of municipalities specifically in developing countries.

Burayu town administration is one of towns in Oromia regional state with deep-rooted improved water supply shortage. The city's water supply and sewerage office was established in 1984.The office was supposed to deliver improved water and administer water utilities for about fifteen thousand city population at that time. According to the town's Administration Office record of 2017, the current population size is estimated to be more than two hundred thousand.

According to water supply and sewerage enterprise the main causes of improved water shortage of the town arises from inadequate cost recovery of service charges and high population growth in the town. The existing water tariff should be revised through cost recovery method based on the affordability of the residents. Therefore, demand side study is required to know the willingness to pay of households for improved water and choose appropriate tariff structure. One way of measuring non-market environmental goods such as water is through collecting and analyzing information on willingness to pay of users for change in quality or quantity of these goods based on their stated preference.

Contingent valuation method is one technique of elicitation of willingness to pay in which we can create hypothetical market for non-market environmental goods in order to collect responses of households on how much they are willing to pay for improvements. It is a technique of putting monetary values on non-market goods depending on the hypothetical market/contingency. It can capture both use and none use values of environmental amenities. This method has being used to value environmental goods of with no actual market price starting from its development in 1947(Haab and McConnell 2002). 
The purpose of this paper is to investigate the existing water service situation of the town and explore the mean willingness to pay of households for improved water service through introducing hypothetical market with CV household surveys.

\section{METHODOLOGY}

This section is deals with methodological procedure of the study which is derived from underlying theories and empirical issues identified in chapter two.

\subsection{Description of the Study Area}

Burayu town is one of districts of Finfinne Surrounding special Zone of Oromia region. It is located to the north west of Addis Ababa, the capital of the country at a distance of $15 \mathrm{~km}$. Its astronomical location is

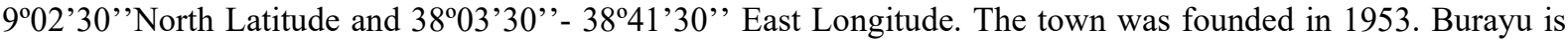
one of the reform towns in the region and has a city administration, municipality and organized in six kebelles. According to the rank given by Oromia National Regional State to all urban centers of the region, the town is one of the first grade towns in the region. Currently the population of the town is estimated to 238113 of which $51 \%$ are females and $49 \%$ are males.

During a informal discussion made with residents they raised improved water service, road (asphalted), street light, drainage canals, and solid waste management are some issues need intervention according to the descending order.

\subsection{Research Design}

Research design is required to facilitate the smooth operation of any research process making research efficient and effective (Kothari 2009). The research design employed in this study is descriptive and explanatory, which best answers the questions raised and meet predetermined objective. Descriptive research describes the characteristics of individuals, groups and situation in relation to something. The nature of this study based on the analysis of the existing phenomenon and deriving at some conclusions. The existing improved water situation was analyzed, the water usage practices of households and their mean willingness to pay is calculated based on the survey responses. In addition to these factors, determining willingness to pay for improvement scenario is identified through drawing relationships. This makes the design share explanatory characteristics.

\subsection{Data type and sources}

This paper primarily used primary data collected from the sample of households' from each kebeles of the town. Before full-fledged data collection, the pretest of questionnaires is conducted with 30 households randomly selected from each kebele. The questionnaire pretest used for two issues.1) to check the questionnaires and make some refinement accordingly. 2) to select the bid value of improved water. In addition to this secondary data from different reliable source is used. Structured questionnaires' was prepared to collect the primary data according to contingent valuation survey method. Random sample technique system is employed to draw sample of households.

\subsection{Contingent Valuation Scenario design}

Currently, the problem of improved water services in Burayu town is critical because of big gap between the amount required and being supplied. The problem arises from high population growth, low water discharging capacities of existing boreholes and inadequate number of boreholes. The construction of additional boreholes, additional water pumps, additional water reservoirs, and the construction of pipelines from the boreholes or other water sources to the pipe require huge financial investments. The town's water supply and sewerage office could not undertake improvement projects due to lack of sufficient financial resources. The current tariff structure does not enable the town's water supply and sewerage enterprise to generate enough funds for to undertake expansion projects. The provision of improved water supply mostly depends on the supply side and which is not effective unless enough budget is assigned. The provision of improved water services to the town's community means provision of good quantity water which is safe for health, availability of good quality of water for 24 hours per day and 7 days per week throughout the year, and also the households save their time and money they used to spend for collecting water from distant sources. Households will get rid of health risks related to water shortage problems and children health improves.

Respondents' thoughtful responses are vital in decision-making process. Depending on this hypothetical scenario, respondents were asked how much they are willing to pay for one Jeri can of improved water of the above characteristics'. The initial investment and operation costs will be added to the monthly water bill, but households may not necessarily pay the initial costs of connection to the new scheme, instead it will be distributed for the next 25 years in monthly bills. This payment schedule was identified during the pre test survey. 


\subsection{Structure of questionnaire}

In this paper the structure of questionnaire, have three sections as indicated in the literature. The first part of it consisted of questions require information on the current situation of improved water service, service level, households perception about quality and quantity of the current improved water service amount and their attitudes regarding to the improvement of the service etc. The second part is questions related to households willing to pay for the improvement projects. The third and final part of the questionnaire consists of the general socio economic and demographic characteristics of respondents such as households' income, education, sex, age, religion, family size, occupation, and etc.

\subsection{Sample Size}

As recommended in theoretical part of this study simple random sampling is appropriate sampling technique to have equal chance of including each household in the sample. A proportional sample of households was obtained using a simple random sampling technique from a list of each kebeles' households. A total of 239 sample respondents were selected proportionally to the size of total households in each kebele.

The sample size was determined according to Kothari (2009) formula.

$$
\mathrm{n}=\quad \begin{aligned}
& \mathrm{z}^{2} \cdot \mathrm{p} \cdot \mathrm{q} \cdot \mathrm{N} \\
& \mathrm{e}^{2}(\mathrm{~N}-1)+\mathrm{z}^{2} \cdot \mathrm{p} \cdot \mathrm{q}
\end{aligned}
$$

Where $\mathrm{n}=$ Sample size

$\mathrm{z}=$ the value of standard variate at the given confidence interval (usually set at $95 \%$ confidence level)

$\mathrm{P}=$ population proportion

$\mathrm{e}=$ margin of error

Accordingly, the total household size of the town is $\mathrm{N}=49607$

Confidence interval of $95 \%(\mathrm{z})=1.96$

Population proportion to be included in the sample taken from pretest response rate $(\mathrm{p})=81 \%=0.81 \mathrm{q}=1-\mathrm{p}=1$ $0.81=0.19$ or $19 \%$

Margin of error $(\mathrm{e})=0.05$ therefore the sample size is calculated as

$\mathrm{n}=\quad(1.96)^{2}(0.81)(.19)(49607)$

$(0.05)^{2}\left(4 \overline{9607-1)+(1.96)^{2}(0.84)(0.19)}=239\right.$

Therefore the study takes a sample of 239 households

\subsection{Sampling Strategies}

Burayu city Administration has six kebeles. Simple random sampling strategy was used while conducting households' survey. Each household has equal probability to be covered by survey. A random sample of the relevant population is best for deriving appropriate inference about that population (Hoyos 2010). This strategy is the easiest for implementation as well.

\subsection{Survey Method}

The survey technique was in personal interview. Personal interview is useful for collecting sufficient and quality information, despite of its cost. This method was recommended by a group of panelists such Arrow et.al at NOAA (National Oceanic and Atmosphere Administration 1993) when they ensured CVM as a good tool in valuation of environmental goods (Carson and McConnell 2002). The interview was made with any household member with age of above fifteen. The household survey took one month from Feb, 1/2017 to Feb 28/2017.It took 30-40 minutes to complete one interview in which interviewee and interviewer are agreed on prior to interviewing process.

\subsection{Methods of Data Analysis}

Data analyses were carried out in both descriptive as well as using econometrics models. The mean, minimum and maximum values socio-economic and demographic status of respondents were calculated and presented in the form of tables and graphs. The STATA 13.1 version soft ware was employed in identifying factors affecting responses and respondents mean willingness to pay for improved water supply.

\subsection{Model Specifications}

The specification of models in this study was according to the standard models of Hanemann (1984) and Haab and McConnel(2002). In contingent valuation method direct elicitation techniques are applied to gather information that affects the willingness to pay of respondents. In practice and theory there are different techniques of asking questions. As described in the theoretical part of this paper open- ended questions are asked directly the respondent in CV method to know the amount he or she is willing to pay. An iterative question formats can also be prepared in the form of bidding game in which the respondent is iteratively asked by increase 
or decreasing the amounts of payments to made depending to the initial response of the respondent. Payment cards with different amounts of payments list is also used in CV elicitation purpose. Respondents are asked to choose among the different values indicated on the card depending on his or her preferences. The dichotomous type elicitation are asked in seek of yes and no responses. This approach has become the widely used elicitation format of $\mathrm{CV}$ practitioners; because the above three formats have problem of incentive compatibility (Haab and McConnell 2002).

The logic behind of estimating parametric models for dichotomous CV formats are important for two reasons: 1) it enables us to incorporate factors affecting the responses of respondents WTP, 2) To estimate the mean WTP given these factors.

Dependent variables of dichotomous nature would be estimated using linear probability, logit or probit models. The outcome of willingness to pay for a given improvement scenario takes discrete values. The probability values of "yes" or "no" could be coded as 1 if yes, 0 otherwise.

$\mathrm{WTP}=\mathrm{F}(\mathrm{X} \beta)=\left\{\begin{array}{l}1 \text { if yes } \\ 0 \text { if no }\end{array}\right.$

With this type of dependent variable the linear probability models have at least the following problems to analyze, (Johnston 2007).The first is that it does not constraint the predicted value between one and zero. The second is the linear probability is heteroskedastic. Third, error terms are non-normal and forth $\mathrm{R}^{2}$ is questionable in measuring goodness of fit. Thus we need to transform the $X \beta$ function in to a probability of $\operatorname{pr}\left(\mathrm{WTP}_{\mathrm{i}}=1\right)=\mathrm{F}(\mathrm{X} \beta)$, thus we can choose logistic either standard normal distribution to transform this function( i.e the functional form of $F()$.$) .$

Since there is no significant difference between logit and probit it is up the researcher to make choose between the two models, (Haab and McConnel 2002).Both distributions are symmetric around the mean. However, their coefficients are not directly comparable.

This study used single bounded followed by open-ended format to estimate the mean willingness to pay and factor determining the maximum willingness to pay of respondents. Open-ended formats were estimated in tobit model because the researcher faced censored responses during collecting data on maximum willingness to pay for improved water services.

\subsubsection{The probit Model}

According to Haab and McConnell (2002) random utility model is the basis for analyzing contingent valuation method survey response. People choose to consume or not consume a bundle of goods depending on their preferences. We cannot correctly model these preferences because of random factors that affect these choices. Random utility theory explains that the utility function is composed of both deterministic and stochastic error factors. The deterministic component is a function of a vector of various attributes of environmental goods.

In valuation process of environmental changes with no actual market price through directly asking people how much to pay for change, the individuals compare two states of environmental goods. One is the state of status quo and the other is the state of improvement relating to their depending on their preferences. Now, the utility of individual is the function of income and other characteristics. Thus the indirect utility function of respondent $j$ will be expressed as:

\section{$U_{i j}=U_{i}\left(y_{j}, z_{j}, \varepsilon_{i j}\right)$.------------------ ---(1a)}

And then, if we introduce the state of improvement by say $\mathrm{q}_{1}$ and status quo as $\mathrm{q}_{0}$ (where $\mathrm{q}_{1}>\mathrm{q}_{0}$ ) the utility function of individual $j$ for status quo is $U_{0 j}=U\left(y_{j}, z_{j}, q_{0}, \varepsilon_{0 j}\right)$ and for the improvement is $U_{1 j}=U\left(y_{j}, z j, q_{1}\right.$, $\varepsilon_{l j}$.). Where $i=1$ is the improvement of environmental good and $\mathrm{i}=0$ is status quo. The factors that affect utility are the individual's income level $\left(\mathrm{y}_{\mathrm{i}}\right)$, vector of household characteristics $\mathrm{Z}_{\mathrm{i}}$ (such as age, sex, occupation, education level and etc.) and attributes of the choice (e.g. quantity, quality, accessibility, etc) and $\varepsilon_{\mathrm{ij}}$, stochastic random variable which is not observable. With this utility representation, the respondent $\mathrm{j}$ can say "yes" to the willingness to pay question for improvement with the new price of $t$ attached to it if the utility derived from improved condition is greater than the status quo. $u_{1}\left(y_{j}-t_{j}, Z_{j}, q_{1}, \varepsilon_{1 j}\right)>u_{0}\left(y_{j}, Z_{j}, q_{0}, \varepsilon_{o j}\right)(1 b)$

But here the stochastic part of random utility is unobservable, the best thing we can do is attaching the probability of saying "yes" or "no" responses towards questions. The probability of respondent $j$ saying "yes" for improvement with payment depends on his or her expectation towards that improvement. That is if he or she perceives that the utility from improvement more satisfies him or her than status quo (i.e. $u_{1}>u_{0}$ ).

For respondent $j$, this probability is

$$
\operatorname{Pr} .(\mathrm{yes})=\operatorname{Pr}\left(\mathrm{u}_{1}\left(\mathrm{y}_{\mathrm{j}}-\mathrm{t}_{\mathrm{j}}, \mathrm{z}_{\mathrm{j}}, \varepsilon_{1 \mathrm{j}}\right)>\mathrm{u}_{0}\left(\mathrm{y}_{\mathrm{j}}, \mathrm{z}_{\mathrm{j}}, \varepsilon_{0 \mathrm{j}}\right)\right)
$$

As parametric estimation of $\mathrm{CV}$ responses required knowing the effects of covariates such as socio-economic characteristics' of individuals and attributes of the good under consideration we describe the above probability in detail. First the functional form of equation (1) can be additively separable to deterministic and stochastic components. The second is the distributional pattern of willingness to pay should be specified.

$$
u_{i}\left(y_{j}, Z_{j}, \varepsilon_{i j}\right)=u_{i}\left(y_{j}, Z_{j},\right)+\varepsilon_{i j}-----(1 d)
$$


With this the probability function of saying yes towards the given question is:

$\operatorname{Pr} .\left(\mathrm{yes}_{\mathrm{j}}\right)=\operatorname{Pr}\left[\mathrm{u}_{1}\left(\mathrm{y}_{\mathrm{j}}-\mathrm{t}_{\mathrm{j}}, \mathrm{z}_{\mathrm{j}}\right)+\varepsilon_{1 \mathrm{j}}>\mathrm{u}_{0}\left(\mathrm{y}_{\mathrm{j}}, \mathrm{z}_{\mathrm{j}}\right)+\varepsilon_{0 \mathrm{j}}\right]$

$=\operatorname{Pr}\left[\mathrm{u}_{1}\left(\mathrm{y}_{\mathrm{j}}-\mathrm{t}_{\mathrm{j}}, \mathrm{z}_{\mathrm{j}}\right)-\mathrm{u}_{0}\left(\mathrm{y}_{\mathrm{j}}, \mathrm{z}_{\mathrm{j}}\right)>\varepsilon_{0 \mathrm{j}}-\varepsilon_{\mathrm{j}}\right]$

$=\operatorname{Pr} .\left[\mathrm{u}_{1}()-.\mathrm{u}_{0}()+.\varepsilon_{1 \mathrm{j}}-\varepsilon_{0 \mathrm{j}}>0\right]$

$=\operatorname{Pr} .[\Delta \mathrm{u}+\Phi]--------------(1 \mathrm{e})$

If $\Phi=\varepsilon_{1 \mathrm{j}}-\varepsilon_{0 \mathrm{j}}$, and $\Delta \mathrm{u}=\mathrm{u}_{1}()-.\mathrm{u}_{2}($.

And Probability of No is:

$$
\begin{aligned}
& \operatorname{Pr} .(\text { no })=1-\operatorname{Pr} .(\text { yes }) \\
& \operatorname{Pr} .\left[\mathrm{u}_{1 \mathrm{j}} \leq \mathrm{u}_{0}\right]=1-\operatorname{Pr} .\left(\mathrm{u}_{1 \mathrm{j}}>\mathrm{u}_{0 \mathrm{j}}\right) \\
& =1-\operatorname{Pr} .[\Delta \mathrm{u}+\Phi>0]-(1 \mathrm{f})
\end{aligned}
$$

Let $\mathrm{S}_{\Phi}($.$) is a cumulative distribution function. This is logit model function if it follows logistic cumulative$ distribution and normal cumulative distribution in probit model.

According to Haab and McConnell (2002), the two models give the same result. The basic difference is that logistic has slightly flatter tails. The probit curve approaches to the axes more quickly than the logistic curve.

The matrix formulation of willingness to pay probability to the single bounded question is given by.

$$
\mathrm{F}_{\mathrm{i}}=\beta^{\prime} \mathrm{X}_{\mathrm{i}}+\varepsilon_{\mathrm{i}}
$$

Where $\beta^{\prime}$ is the vector of parameters of the model $X_{i}=$ the vector of explanatory

$\varepsilon_{\mathrm{i}}=$ Stochastic error term, which is normally distributed with mean zero and constant variance. $\mathrm{F}_{\mathrm{i}}$ is unobserved households willingness to pay for improved water services in our case, which is latent variable or threshold. Here what is observable is when WTP $\left(F_{i}\right)$ is greater than zero. ( i.e $\left.\mathrm{WTP}>0\right)$. WTP $=\mathrm{ifF}_{\mathrm{i}} \geq \beta_{\mathrm{i}}{ }^{*}$ (1h)

$$
\mathrm{WTP}_{\mathrm{i}}=0 \mathrm{ifF}_{\mathrm{i}}<\beta_{\mathrm{i}}{ }^{*}
$$

Whenever the respondent is asked his or her willingness to pay for the improvement provided with a given price $\left(\beta_{i}^{*}\right)$ the probability of "yes" or "no" is evaluated as a random utility maximization choice. The individual knows his/her maximum amount of contribution; however, for the researcher it is difficult. Therefore the random variable with $\mathrm{CDF}$ denoted by $\mathrm{S}\left(\mathrm{F}_{\mathrm{i}}, \Phi\right)$, $\Phi$ is parameter of distribution. The two possible response probabilities in single bounded dichotomous format are either yes or no to the question of bid value of improved water.

$\operatorname{Pr}$. $($ yes $) \equiv \operatorname{Pr}$. $\left(\right.$ yes to $\left.\beta_{\mathrm{i}}^{*}\right) \equiv \operatorname{Pr} .\left(\beta_{\mathrm{i}}^{*}<\mathrm{F}_{\mathrm{i}}\right)=\mathrm{S}\left(\mathrm{F}_{\mathrm{i}}, \Phi\right)$

(1j) $\operatorname{Pr}$. (no $) \equiv \operatorname{Pr}$. $\left(\right.$ no to $\left.\beta_{\mathrm{i}}{ }^{*}\right) \equiv \operatorname{Pr} .\left(\beta_{\mathrm{i}}{ }^{*}<\mathrm{F}_{\mathrm{i}}\right)=1-\mathrm{S}\left(\mathrm{F}_{\mathrm{i}}, \Phi\right)$

The estimation process follows the log likelihood function (Green 2011)

$\ln \mathrm{L}(\Phi)=\Sigma\left\{\mathrm{z}_{\mathrm{i}}^{\mathrm{y}} \ln \mathrm{S}\left(\beta_{\mathrm{i}}, \Phi\right)+\mathrm{z}_{\mathrm{i}}^{\mathrm{n}} \ln \left[1-\mathrm{S}\left(\beta_{\mathrm{i}}^{*}, \Phi\right)\right]\right\}$

Where $z_{i}{ }^{y}=1$ if the $i^{\text {th }}$ response is "yes" and 0 , otherwise; $z_{i}{ }^{n}=1$ if the $i^{\text {th }}$ response is no and 0 otherwise.

$\mathrm{S}\left(\beta_{\mathrm{i}}{ }^{*} \Phi\right)$ and $1-\mathrm{S}\left(\beta_{\mathrm{i}}{ }^{*}, \Phi\right)$ are the cumulative distribution function (cdf) for the probability of yes and no responses; and $\Phi$ represents the vector of parameters that index the distribution of WTP.

One of the aims of parametric estimation of dichotomous choice responses in studying WTP is to incorporate factors affecting the willingness to pay of households (Haab and McConnell 2002). The other is to estimate the mean willingness to pay for the improvement to be made in quality, quantity or other attributes of environmental goods. The probit model for estimation of a household willingness to pay for improved water services is:

$\mathrm{WTP}_{\mathrm{i}}=\beta_{0}+\beta_{1} \mathrm{Incm}+\beta_{2} \mathrm{Hhh}+\beta_{3} \mathrm{Edu}+\beta_{4} \mathrm{Ocps}+\beta_{5} \mathrm{Fms}+\beta_{6} \mathrm{Qtt}+\beta_{7} \mathrm{Qlt}+\beta_{8}$ Hous $+\beta_{9}$ Sors $+\beta_{10}$ Age $+\beta_{11}$ Gndr $+\beta_{12}$ Hsharedtlt $+\beta_{13}$ Lvsat $+\beta_{14}$ Mrst $+\beta_{15}$ Bidv $+\varepsilon_{i}$

According to Haab and McConnel(2002) the mean willingness to pay is calculated as

Mean WTP $=\mu=-\beta_{0} / \beta \quad$ Where $\beta_{0}$ is intercept (constant) $\beta$ is coefficient of bid price

\subsubsection{The Tobit Model}

Tobit model ( censored regression) is appropriate model when dependent variable is continuous but constrained in some ranges (Verbeex 2012). The model is used when some values of dependent variable is non-negative zero and the other part is different outcomes. When data is censored, the appropriate distribution of the model is the mixture of discrete and continuous distribution (Green 2011 p.886). In this study open-ended CV format was analyzed by tobit model to estimate the maximum amount households are willing to pay for improved water service. In eliciting maximum willingness to pay through open ended formats some respondents gave true zero maximum willingness to pay for improved water. Therefore, some values of our dependent variable of maximum willingness to pay (MWTP) are zero. To capture this problem tobit model is appropriate for estimation. From 217 useful responses 12 respondents replied that the maximum amount they willing to pay is true zero. Tobit model is also used to identify factors that determine the maximum amount of money the respondents are willing to pay for improved water.

Following the general formulation of tobit model in Green (2011) $Y_{i}^{*}=X^{\prime} \beta+\varepsilon_{i}$ (3a) 


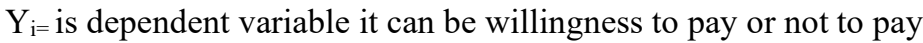

$\mathrm{X}^{\prime}=$ explanatory variable

$\varepsilon_{\mathrm{i}}=$ Normally distributed stochastic random variable with mean $\mu$ and constant variance $\sigma^{2}$.

Assume that there is perceived utility (U) for paying for improved water service.

$\mathrm{U}_{\mathrm{i}}=1 \quad$ if $\mathrm{U}_{\mathrm{i}}^{*}>0$ paying for an improved water supply

$\mathrm{U}_{\mathrm{i}}=0 \quad$ if $\mathrm{U}_{\mathrm{i}}^{*}<0$ for not paying

$\mathrm{U}_{\mathrm{i}}^{*}$ is unobserved latent variable or the threshold, observed only if WTP is non-negative number greater than zero.

The expected value of $U$ is:

$\mathrm{E}(\mathrm{U})=\mathrm{X}_{\mathrm{i}} \beta \mathrm{F}(\mathrm{Z})+\delta \mathrm{f}(\mathrm{Z})$

Where $\mathrm{X}=$ vector of explanatory variable

$\mathrm{Z}=$ cumulative distribution function

$\mathrm{Z}=\mathrm{is}$ given as $\mathrm{X} \beta / \delta$

$\beta=$ vector of tobit maximum likelihood estimates

$\delta=$ standard error

The mean of all observation and conditional value above the limit of mean $U^{*}$ is

Mean of $\mathrm{U}=\mathrm{F}(\mathrm{Z})$ Mean $\mathrm{U}^{*}$

Then the Loglikelihood of the tobit model is

$\ln L=\sum\left[-1 / 2\left(\log (2 \Pi)+\ln \delta^{2}+\left(\mathrm{U}_{\mathrm{i}}-\mathrm{X}^{\prime} \beta\right)^{2}\right]+\sum \ln \left[1-\phi\left(\mathrm{X}^{\prime} \beta\right)\right.\right.$

Maximizing the likelihood function with respect to $\beta$ and $\delta$ will give as the estimation of these parameters. The maximum willingness to pay responses to $\mathrm{CV}$ questions will be regressed against the households' socioeconomic characteristics and water attributes.

Thus, the tobit model for maximum willingness to pay estimated in this study has the form of:

$\mathrm{U}_{\mathrm{i}}=\mathrm{MWTP} *$ if $\mathrm{MWTP}^{*}>0,=0$ if $\mathrm{MWTP} \leq 0=0$

Here the vector maximum willingness to pay for improved water service was censored from the left at zero, as some responses contain true zero willingness to pay. This means we can only see the maximum amount to pay if the response is greater than zero value.

Model to be estimated in this research paper is

$\mathrm{U}_{\mathrm{i}}=\mathrm{MWTP}_{\mathrm{i}}=\beta_{0}+\beta_{1} \mathrm{Incm}+\beta_{2} \mathrm{Hhh}+\beta_{3} \mathrm{Edu}+\beta_{4} \mathrm{Ocps}+\beta_{5} \mathrm{Fms}+\beta_{6} \mathrm{Qtt}+\beta_{7} \mathrm{Qlt}+\beta_{8}$ Hous $+\beta_{9}$ Sors $+\beta_{1}$ Age $+\beta_{11}$ Gndr $+\beta_{12}$ Hshar edtlt $+\beta_{13}$ Lvsat $+\beta_{14} \mathrm{Mrst}+\beta_{15} \mathrm{Bidv}+\varepsilon_{\mathrm{i}}$

\section{DATA ANALYSIS AND DISCUSSION OF RESULTS}

This section deals with procedures of data analysis and discussion based on the results of survey. The analysis was made in both methods as described in the methodology part. Both descriptive and econometric analyses were done. The socio-economic and demographic status, the existing improved water supply services and aggregation of willingness to pay were done descriptively and presented in the form of tables and graphs. Factors affecting the decision of willingness to pay, mean value of willingness to pay were analyzed using econometric models. Two likelihood estimators of econometrics models were used in the empirical analysis of data separately. The mean willingness to pay and the factors affecting willingness to pay for improved water is analyzed from closed ended formats with probit model. The maximum willingness to pay of responses of open-ended format and determining factors were analyzed using tobit model. The analysis of this study made with the aid of STATA 13.1 version software.

\subsection{Socio-economic and Demographic Analysis of Respondents}

In this study a total of 239 households were interviewed. However due to inconsistency of responses about 22 questionnaires were excluded from analysis and therefore 217 complete questionnaires were used for analysis purposes. Of the sampled households $98(45.16 \%)$ are male and $119(54.84 \%)$ are female. The marital status shows that $161(74.19 \%)$ respondents are married and $56(25.81 \%)$ are others (such as single, divorced and widowed).Out of 217 respondents $179(82.49 \%)$ are head of their family and $38(17.51 \%)$ are not. The mean average age of respondents is 36.6 years of which 16 years is minimum and 75 years is maximum. 177( $81.57 \%)$ respondents have got formal education and 40(18.43\%) they are illiterate. From 177 literate 62(35\%), 58(32.8\%) and $65(32.4 \%)$ respondents' completed primary (1-8), secondary (9-12) and tertiary $(>12)$ educations levels respectively.

The occupation status of respondents shows that $49(22.58 \%)$ are government employees, $22(10.14 \%)$ in private business, 56(25.81\%) are housewives, 27(12.44\%) students, 39(17.97\%) self-employed, 19(8.76\%) unemployed and 5(2.3\%) individuals were unemployed. Totally $122(56.22 \%)$ are employed in different government and other institutions with salary and 95(43.78\%) are not salary employed.

The average monthly income of households was estimated to be 4746.6 birr with the minimum of 500 birr 
and 24000 birr maximum. Average monthly expenditure of households is 3401.244 birr with the minimum of 500 birr and 12000 birr maximum. The average family sizes of households were about 4.8 with the minimum of 1 to 10 persons. The mean number of adult group which are more than or equal to fifteen years old is 3.13 with the minimum of 1 and maximum 8 adults.

Of 217 respondents $137(63.13 \%)$ have their own house and $80(36.87 \%$ ) have not. The interviewed households were living in the area for 7.71 years in average with the minimum of two months and maximum of thirty-five years.

\subsection{The Current Improved Water Supply Services and Households Water Usage Practices}

Currently, there are about 13 boreholes of different size producing improved water constructed by the town's water supply enterprise. The total capacity of water production per day is about 5443200litres $\left(5443.2 \mathrm{~m}^{3}\right)$ according to the office 2017 report. This amount of improved water is consumed by household, factories, commercial activities (such as hotels, restaurants, cafeterias, recreational sites etc.), and government and nongovernment institutions.

The town's water supply and sewerage enterprise provides water in shift bases. From the surveyed households the current average daily water consumption of household is about 57.2 liters (i.e. 2.86 Jeri can of 20 liters). Majority of households store water in different storage materials and try to smooth their consumption at least for fifteen days. The improved water coverage of the town is currently estimated to $55.1 \%$ according to the office. This implies that huge number of population is still waiting for improved water supply services. The current total revenue being collected from service charges of water provided to households is on average estimated to 515,009.95 birr per month. The town's water supply and sewerage enterprise has currently around 27313 customers including households and other institutions (such as factories, commercial business, and government and non-government intuitions').

The primary concern of this paper is to analyze households' water consumption and their willingness to pay for improvement. Of 217 respondents 197(90.78\%) use piped water and 20(9.22\%) non-piped (such as wells $16(80 \%)$ and $4(20 \%)$ springs). Respondents asked whether the quantity of water they get per their respective day is sufficient or not. About $165(76.04 \%)$ respondents perceived that the quantity of current water delivered is poor with low pressure. Only 52(23.96\%) of respondents replied that the quantity of water they are getting is good. Regarding to the quality of water $113(52.07 \%)$ respondents said the water is poor which is characterized by bad smell and sometimes muddy. The rest 104(47.93\%) respondents replied that the water is clean. The surveyed households in average get improved water provision 6 days within a month with the minimum of 1 day and maximum 30 days. Of 171 who use pipe $83.73 \%$ fetch water below four days and the rest $16.27 \%$ fetch pipe water from five to thirty days per month.

Households' average monthly water expenditure is 26.5 birr which is $0.67 \%$ of their mean monthly income. This implies that there is still high potential to pay for improved water services in the town. The daily-improved water consumption of households is on average about 2.86 Jeri can (i.e. 57.2 liters). The per capita water consumption of households is 11.9liters per day. This is by far below what the WHO recommends, which is 25 liters per person per day (WHO 2003). Among 217 respondents only 69(31.80\%) own water tanker to cope up with water shortage and $148(68.20 \%)$ have no.

Respondents were also asked to state whether they are satisfied with the current improved water services provided by the town's water and sewerage enterprise, and out of 217 respondents $172(79.26 \%)$ are not satisfied and only $45(20.74 \%)$ said they are satisfied. When they are asked to state their reason of dissatisfaction to the existing improved water provision services $170(89 \%)$ of respondents stated that the quantity and low pressure are the main causes. The rest $47(11 \%)$ respondents explained the quality and distance of the source are the main causes of their dissatisfaction. Majority of the respondents use water obtained from different sources for drinking, washing clothes, housecleaning and others. Of 46 surveyed respondents, using public fountains and other sources revealed that they waste about 2 hours in average to bring water back to their home per day from those sources.

From above table of 217 sampled households, 20 of them use water collected from non pipe sources which is low quality and not safe for health. Of 28 respondents who responded that they experienced from water related disease 18 of them are non-pipe users. Most of the time girls $(18 \%)$ and women $(52 \%)$ are responsible to fetch water for household consumption from those sources.

\subsection{Households' Willingness to pay for Improved Water Services}

Of 119 female respondents 106(89.1\%) were willing to accept the improvement bid values. Only 13(10.9\%) refused the bid. Among 98 male respondents 56(57.1\%) are willing to pay the bid value and 42(42.9\%) were rejected the improvement. In other way among 161 married respondents $125(78 \%)$ of them were positive to pay the provided bid value of improvement, however 36(22\%) refused. Household heads who were accepting the bid value also significant in number. Of 179 household heads $138(77.1 \%)$ were willing to pay for improved water. About 41(22.9\%) household heads refused the improvement price. 
Among 160 educated respondents $147(92 \%)$ were willing to pay and only $13(8 \%)$ of them refused the price. Moreover, of 95 employed respondents 85(89.5\%) accepted the bid value of improvement. 10(10.5\%) respondents were not willing to pay this price. Out of 52 respondents who said the quantity of water is good only $19(36.5 \%)$ were willing to pay, however majority 33(63.5\%) were not willing to pay for improvement. Of 113 respondents saying the quality of water was poor of $87(77 \%)$ them accepted the bid value and $26(23 \%)$ refused to pay the given improvement bid price. Among 172 unsatisfied respondents with the current water supply services $146(85 \%)$ were willing to pay and only $26(15 \%)$ refused the bid value.

Of 171 pipe users 123(72\%) accepted the bid of improved water. From 26 public fountain users 19(73.1\%) are willing to pay some amount for improved water. Among 20 who are using non-pipe 18(90\%) accepted the bid value.

Table 3.7. Households' willingness to pay with type of schemes

\begin{tabular}{|l|l|l|l|}
\hline \multirow{2}{*}{ WTP } & \multicolumn{2}{|c|}{ Type of pipe water } \\
\cline { 2 - 4 } & Private Pipe & Public fountain & Non-pipe Users \\
\hline No & 48 & 7 & 2 \\
\hline Yes & 123 & 19 & 18 \\
\hline Total & 171 & 26 & 20 \\
\hline Percent "yes" responses & 72 & 73.1 & 90 \\
\hline
\end{tabular}

Source: Own survey 2017

In this study four bid values were introduced for improved water services. These prices were selected during pretest of questionnaires with the open ended question format provided for 30 respondents randomly selected from each kebele. The mode of those values was taken and 20,30, 40 and 50 cents were selected as starting values of improved water per 20 liters of Jeri can. The 20 liters Jeri can is used as unit of measurement because almost every household are familiar with this material. These values were randomly distributed to 239 respondents in the equal proportion. Finally, 217 useful responses were considered for analysis purposes. About 22 inconsistent responses are excluded from the analysis. From 217 respondents 160(73.73) replied "yes" and $57(26.67 \%)$ respondents said "no" to the initial bid of improved water services. The following table summarizes the bid price and corresponding willingness to pay for those prices.

Table 3.8: Summary of Bid value and Willingness to pay for Initial bid

\begin{tabular}{|l|l|l|l|}
\hline \multirow{2}{*}{ Bid value } & \multicolumn{2}{|c|}{ Willingness to payal } \\
\cline { 2 - 3 } & No & Yes & \\
\hline 20 & 3 & 57 & 60 \\
\hline 30 & 9 & 48 & 57 \\
\hline 40 & 20 & 29 & 49 \\
\hline 50 & 25 & 26 & 51 \\
\hline Total & 57 & 160 & 217 \\
\hline
\end{tabular}

Source: Own Survey 2017

The above table shows that of the four bids provided to respondents 57 accepts 20 cents and only 3 respondents refuse this amount. Of total respondents provided with 30 cents for one Jeri can of improved water 48 reveal their willingness to pay and 9 respondents rejected. In the same scenario 40 cents was randomly distributed to respondent of which 29 replied yes and 20 didn't accept. Finally, 26 respondents accepted 50 cents of bid value of improved water and 25 rejected this amount.

Respondents were also provided with open ended question of the maximum willingness to pay for improved water services. Out of 217 respondents' 205(94.47\%) gave greater than zero values for improved water services with a minimum of 10 cents to the maximum of 100 cents. About $12(5.53 \%)$ respondents expressed their true zero maximum willingness to pay for improved water service, of which $6(50 \%)$ said that the current improved water provision service in enough for them, 3(25\%) explained that they hesitate that the money will be misused, $2(16.67 \%)$ of them saying they have no enough money to make any payment and $1(8.83 \%)$ hesitated that the improvement will not be realized depending on his perception of previous broken promises.

Table 3.9: Summary of Respondent Maximum Willingness to Pay

\begin{tabular}{|l|l|l|l|l|}
\hline Bid values & Mid value & Freq & Percent & Cum \\
\hline $0-20$ & 10 & 62 & 28.57 & 28.57 \\
\hline $21-40$ & 30.5 & 66 & 30.41 & 58.98 \\
\hline $41-70$ & 55.5 & 67 & 30.9 & 89.88 \\
\hline $71-100$ & 85.5 & 22 & 10.14 & 100 \\
\hline
\end{tabular}

Source: Own Survey 2017

From the above table we can see that $62(28.57 \%)$ households are willing to pay about 10 cents in average, $66(30.41 \%)$ willing to pay 30.5 cents, $67(30.9 \%) 55.5$ cents and $22(10.14 \%)$ are willing to pay 85.5 cents for improved water services in open ended format. The maximum mean willingness to pay for improved water is 
42.79 cents per one Jeri can of 20 liters.

From the closed ended format, the mean willingness to pay for water service was estimated to 31.5 cents per 20 liters of Jeri can. When we compare this amount to the current tariff structure of the town's water supply and sewerage enterprise it is much higher. In the following table shows the current tariff structure of Burayu town water supply and sewerage enterprise.

Table 3.10: Burayu town Water Supply and Sewerage Enterprise Current Water Tariff Structure

\begin{tabular}{|c|c|c|c|}
\hline \multirow{2}{*}{ S.No. } & Quantity in $\mathrm{m}^{3}$ & Cost birr $/ \mathrm{m}^{3}$ \\
\cline { 2 - 4 } & From & To & 4.50 \\
\hline 1 & 0 & 5 & 5.25 \\
\hline 2 & 4 & 8 & 6.00 \\
\hline 3 & 6 & 11 & 6.75 \\
\hline 4 & 9 & $>$ & 7.50 \\
\hline
\end{tabular}

Source: Burayu town Water Supply and Sewerage Enterprise 2017

As shown in the above table the tariff structure of the town's water supply and sewerage enterprise is progressive. The consumption of $0-3 \mathrm{~m}^{3}$ prices is $4.5 \mathrm{birr}, 4-5 \mathrm{~m}^{3}$ price is 5.25 birr, $6-8 \mathrm{~m}^{3}$ charges 6.00 birr, for the consumption of $9-11 \mathrm{~m}^{3}$ the price is multiplied by 6.75 and 12 and more $\mathrm{m}^{3}$ the service charge is multiplied by 7.50 birr. For example if assume a given household consumed $3 \mathrm{~m}^{3}$ (3000litres) they will be charged $3 * 4.50=13.50$ birr. Within these blocks category with the existing tariff structure one Jeri can of 20 liters is estimated to 9 cents in the first block. In the same fashion in $4-5 \mathrm{~m}^{3}$ block 11 cents, in $6-8 \mathrm{~m}^{3}$ block 12 cents, in 91113.50 cents and in above $12 \mathrm{~m}^{3}$ block 20 liters of improved water costs 15 cents. Therefore, these series service charges are by far lower than what households are willing to pay for water improvements. This clearly implies that if the town's water supply and sewerage enterprise construct new expansion projects and expand private pipe connections it will collect sufficient revenue and able to sustain the improved water provision services.

\subsection{Determinants of Willingness to pay}

In this study single bounded dichotomous followed by opened ended formats were used to elicit households' willingness to pay for improved water service. Some important socio economic issues of respondents and the existing water characteristics' were included in the model. These determining factors were selected depending on their theoretical relevancies' and statistical significances.

Before econometrics analysis is done data were checked for existence of severe colleniarities among independent variable and pair wise correlation was run (Annex 1). The result showed that there is some variables severely correlated and due to this between the two correlated variables one variables was dropped. Number of adults is excluded because of high pair wise correlation with family size. In this case the researcher used the correlation standard indicated in most literature which is 0.75 for an indication of severe colliniarty.

The two models specifications were also tested separately using link test (Annex 2 and 4) to check for the functional form of willingness to pay miss specification. From the result the hat square value is insignificant which means that there were no model misspecifications. The other issue is the issue of heteroskedasticity problem, which is common in cross-sectional data analysis. For these reasons robust standard errors was calculated.

\subsubsection{Probit Analysis and Determinants of households' preference for improved water service}

The closed ended format of willingness to pay for improved water was analyzed using probit model given bid value and other factors. In this model, the mean willingness to pay and factors affecting the probability of willingness to pay for bid value of improved water were analyzed. 
Table 3.11: The likelihood Results of Probit Model and result of Determinants of households' preference for improved water service

$$
\begin{array}{lr}
\text { Number of obs. }= & 217 \\
\text { Wald chi }{ }^{2}(15)= & 84.21 \\
\text { Prob }>\text { chi }^{2}= & 0.0000
\end{array}
$$

Log pseudo likelihood $=-124.95599$

Log pseudo likelihood $=-32.159908$ Pseudo $\mathrm{R}^{2}=0.7426$

\begin{tabular}{|l|l|l|l|l|}
\hline Variables & Coef. & $\begin{array}{l}\text { Robust } \\
\text { Std.Err }\end{array}$ & Z & Marginal effects dy/dx \\
\hline Gdr & 0.5614621 & 0.4027556 & $1.90^{* * *}$ & 0.0502125 \\
\hline Mrst & 0.9040885 & 0.5614398 & $1.95^{* * *}$ & 0.0801908 \\
\hline Hhh & 0.4153728 & 0.7074776 & 0.77 & 0.035272 \\
\hline Age & -0.0236556 & 0.0160586 & $-1.76^{* * *}$ & -0.0019239 \\
\hline Fms & 0.0122152 & 0.10716 & 0.15 & 0.0009934 \\
\hline Incm & 0.0002939 & 0.0000934 & $4.53^{*}$ & 0.0000239 \\
\hline Ocps & 1.637672 & 0.5050565 & $2.77^{*}$ & 0.1419839 \\
\hline Edu & 1.551091 & 0.4803709 & $2.11^{*}$ & 0.162718 \\
\hline Hous & -0.2123388 & 0.4684541 & -0.52 & -0.017227 \\
\hline Sors & -2.215673 & 1.237734 & $-2.97^{*}$ & -0.1582985 \\
\hline Qtt & -1.005363 & 0.4674942 & $-2.30^{* *}$ & -0.099805 \\
\hline Qlt & -1.013209 & 0.4613176 & $-3.05^{*}$ & -0.0868983 \\
\hline Lsat & 1.829275 & 0.5103038 & $2.52^{*}$ & 0.2068423 \\
\hline Bidv & -0.1034475 & 0.0247265 & $2.28^{*}$ & -0.0086306 \\
\hline Hsharedtlt & -0.1266883 & 0.0994378 & -1.62 & -0.0103078 \\
\hline Constant & 3.255703 & 1.688623 & 2.91 & \\
\hline
\end{tabular}

$*$ p-value $<0.01, * * \mathrm{P}$-value $<0.05, * * * \mathrm{P}$-value $<0.1$

Source: Own Survey 2017

Note: $\mathrm{dy} / \mathrm{dx}$ is for discrete change of dummy variable from 0 to 1

The variable of household income has a positive and significant effect on the decision of willingness to pay for improved water. Income is a fundamental variable, which influence the decision of choice of people. Economic theory explains that when the disposable income level increases the demand for normal good will increase. Therefore, income and willingness to pay for improved water has positive relationship as far as water is assumed as normal good. As the result shows, the marginal effect of income is significant at $1 \%$. Keeping other factors at their mean, a birr increase in average monthly income of household will increase the probability of accepting the improvement bid value by 0.0024 percentage points.

Education level of respondents has also positive as expected and statistically significant at $1 \%$ level. Educated respondents are more willing to pay more than uneducated respondents are. Moreover, the marginal effect of education shows that keeping other independent variables constant the probability of saying yes to the given bid value of improved water increases by $16.3 \%$ for educated than their counterfactuals. The result is consistent with Bogale(2012), Tamirat(2013) and Mvengeli(2015). The possible reason is that educated people are more concern to their health and seek improvement in improved water provision.

Source of water for household consumption is important and significant variable in this model. It was negative as expected and both coefficients of parameter and marginal effect are significant at $1 \%$. This shows that piped water users are less likely to accept the improvement bid value than non-piped water users keeping other factors constant. The marginal effect shows the probability of accepting bid value decreases by $15.8 \%$ for piped water users other factors keeping constant.

Another important variable in this model was occupation status of respondents. During data collection we identified that respondents have different forms of employment status such government, private, self-employee, housewife students and other. The result shows that formally salary employed respondents are more willing to pay for improved water bid value than their counterfactual. This is because employed respondents' earn stable income and are able to make payments. The marginal effect of occupation status is also significant at $1 \%$ significance level. This implies that being formally employed increases the likelihood of willingness to pay by $14.2 \%$ when compared to unemployed ones.

Respondents were asked if they are satisfied with the existing improved water supply services. The expected sign of this variable was positive. As expected, the sign of Lsat was positive and significant. The marginal effect was also positive and significant at $1 \%$ significance level. Keeping other variables constant, the probability of saying yes for provided bid value of improved water increases by 20.7 percentage points if respondent is unsatisfied than who is satisfied. 
The amount of bid value provided to the respondents is also a very interesting and statistically significant variable to accept or not the improvement value. The coefficient on bid value and marginal effects have negative sign and significant at $1 \%$ significance level. As bid value increase by one cent the probability of accepting it will be reduced by 0.86 percentage points other factors holding constant. This is relevant with economic theory of demand, which says as the price of normal good increases the demand of that good decreases citrus paribus.

The above probit results the gender of respondent is positive as expected and significant at $10 \%$ significance level. In addition to this, the marginal effect of gender is also significant at $10 \%$ level. This shows that being a female increases the probability of accepting a given bid value of improved water by $5 \%$ keeping other covariates constant. This result is consistent with the study results of Bogale and Yibeltal (2011). It may be due to the fact that majority of household activities required water are done with women. That means women are more concerned with cooking and washing activities in household and directly affected by water problems than male.

Marital status is also important variable in probit model, which is positive and significant at $10 \%$.It, shows that the chance of accepting the provided bid value is higher for married individuals than their counterfactuals. Its marginal effect indicate that the probability of saying yes to the bid price of improved water increases by $8.01 \%$ for married respondents than single individuals citrus paribus. This is because married couple consumes more water and they are careful about their family's health.

Respondents who are household head are positive to accept the bid value of improved water. However, the marginal effect of this variable is statistically insignificant. The coefficient of age of respondents' was found to be negative and also significant at $10 \%$ significance level. This finding is also the same with the results of Fikadu, Tamirat(2013) and Mvangeli(2015). This indicated that as age of respondents increased their willingness to pay for improvement erodes. The possible reason may aged people took coping measures and are not willing to pay for improvement. In addition to this aged people want to preserve the status quo, because they used most of their life period.

Family size has positive relationship with willingness to pay for improved water services because large family size expected to consume more water. The direction of influence of this variable is not consistent with most of previous studies. However, consistent with the study result of Ayanshola(2013) and Kadisa (2013). This shows that as family size increases the probability of accepting the improvement bid also increases, because large family size consume more water and they can share the cost, specially whenever employed number of adults is large in the family. However, this variable is not statistically significant.

The perception of respondents for quantity of water released has an effect on the decision to pay or not for a given bid value of water improvement scenario. The coefficient is negative as expected and significant at $5 \%$. The p-value of its marginal effect also shows significance at the same level. From the marginal effect result we can conclude that the probability of saying yes to the bid value of improved water per given unit of measurement decreases by $10 \%$ for respondents who says good than poor keeping other variables constant.

Quality of water existing water is also proved to be important factor to alter the willingness to pay for improvement. It is significant at $1 \%$ significance level and its sign is negative as expected. The marginal effect is also significant at the same significance level. Respondents who perceive the quality of water is safe willing less to pay for the given bid value. Other covariates being constant the probability of accepting bid value less by $8.7 \%$ for those respondents who perceive it as good than satisfied respondents.

More over the coefficients of Bid value and constant are significant at one percent significance level. According to Hahnemann (1991) one of the main objectives of parametric estimation of the willingness to pay depending on contingent valuation method is to calculate the mean value. Following Haab and McConnel(2002) statistical formulation of mean willingness to pay for improved water per 20 liters of Jeri can from single bounded dichotomous format is:

$$
\begin{aligned}
\text { Mean WTP }=-\alpha / \beta \\
=-3.255703 /-0.1034475=31.5 \text { cents }
\end{aligned}
$$

Therefore the mean willingness to pay for improved water obtained from closed ended format is 31.5 cents per 20 liters of Jeri can.

\subsubsection{Tobit Model Regression}

The determinants of households' maximum willingness to pay for improved water services were analyzed using censored regression of tobit model. As explained in the theoretical part of this study censored regression models are used for non-negative dependent variable with some zero values. Estimating parameters using OLS if we have censored dependent variable leads to bias and inconsistency of parameters (Green 2011). Therefore, the maximum willingness to pay for improved water is regressed against socio-economic characteristics of respondents and some water attributes. The maximum willingness to pay of respondents' is censored at zero from the left. Here MWTP is a latent variable that could be seen if its value is greater than zero (MWTP $>0$ ). 
decreases the probability of paying maximum amount for improved water by 16.15 than non-pipe users, keeping other factors constant. This shows that non-piped water users are more likely to pay more than piped users. It is not surprising because non-pipe water users suffer a lot relating to the shortage of improved water. Poor quality of water brought from these sources, long distance of journey and wastage of time in queuing make them pay more for improvement scenario. They wish to have private pipe connection if the improvement scenario is come to effect. However, pipe users may establish coping mechanisms and they are not willing to participate in improvement.

The amount of bid value provided to the respondents is also a very interesting and statistically significant variable in tobit model. The coefficient on bid value has negative sign and significant at $5 \%$ significance level. As bid value increases respondents maximum willingness to pay would decrease. This is relevant with economic theory of demand, which says as the price of normal good increases the demand of those good decreases. The marginal effect also shows that a one cent increases of improved water bid value will reduces the willingness to pay by 0.28 cents, keeping other covariates constant.

Finally the maximum mean willingness to pay for improved water per one Jeri can of 20 liters from open ended format is simply calculated as dividing the total sum of maximum willingness to pay of respondents to the number of sampled households. Thus the total sum of maximum willingness to pay ( $\Sigma$ MWTP) is 9285 cents.

Mean $\mathrm{MWTP}=\Sigma \mathrm{MWTP}_{\mathrm{i}} / \mathrm{n}=9285 / 217=42.79$ cents

Figure 2: Total Revenue of Improved water per month

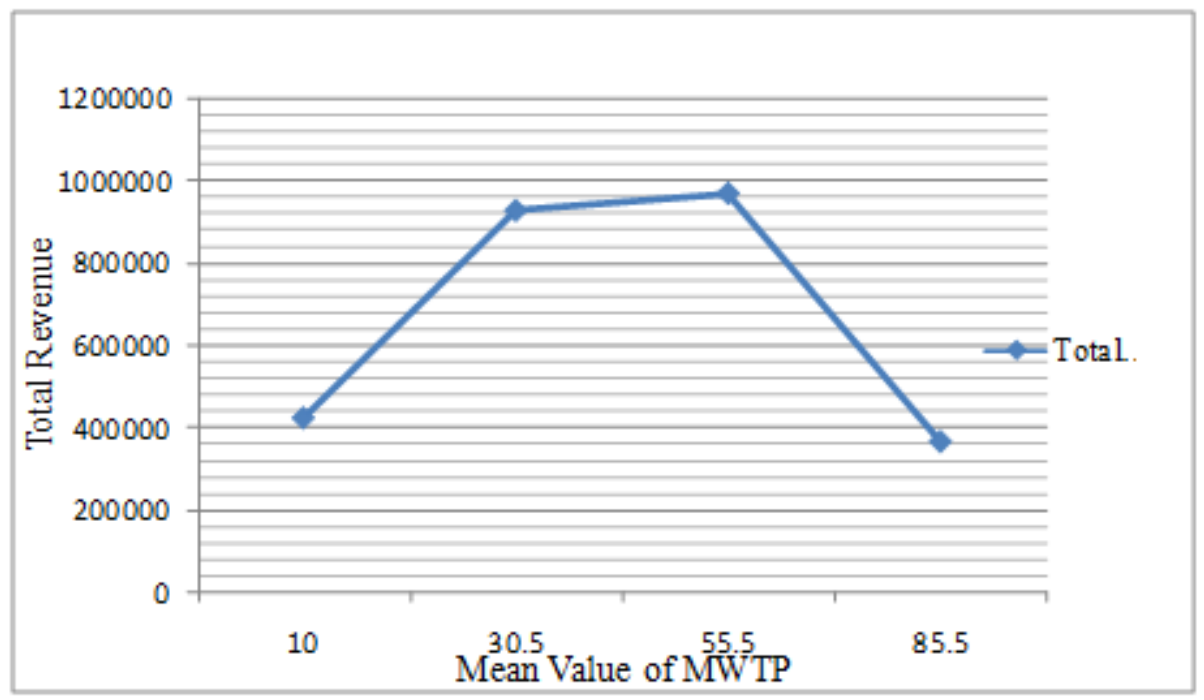

Source: Own Survey 2017

Therefore this result implies that if the improvement program is undertaken by the town's water supply and sewerage enterprise it not only solves the shortage of improved water supply services but also improves the revenue collected from water services which enables to sustain the service and expand the provision.

The researcher derived the demand curve for improved water of households against the mid value of maximum willingness to pay. As shown below the demand curve of improved water is similar with the shape of other normal goods demand curves. The demand curve of normal good is downward sloping showing that the quantity demanded and price is negatively related. Analogously in this study as the service charge of water increase (the bid value in our case) the demand will fall down. This curve shows that the number of households willing to pay the maximum amount (horizontal axis) and the amounts of bid values in cents (vertical axis). 
Figure 3: Demand Curve for Improved Water Services

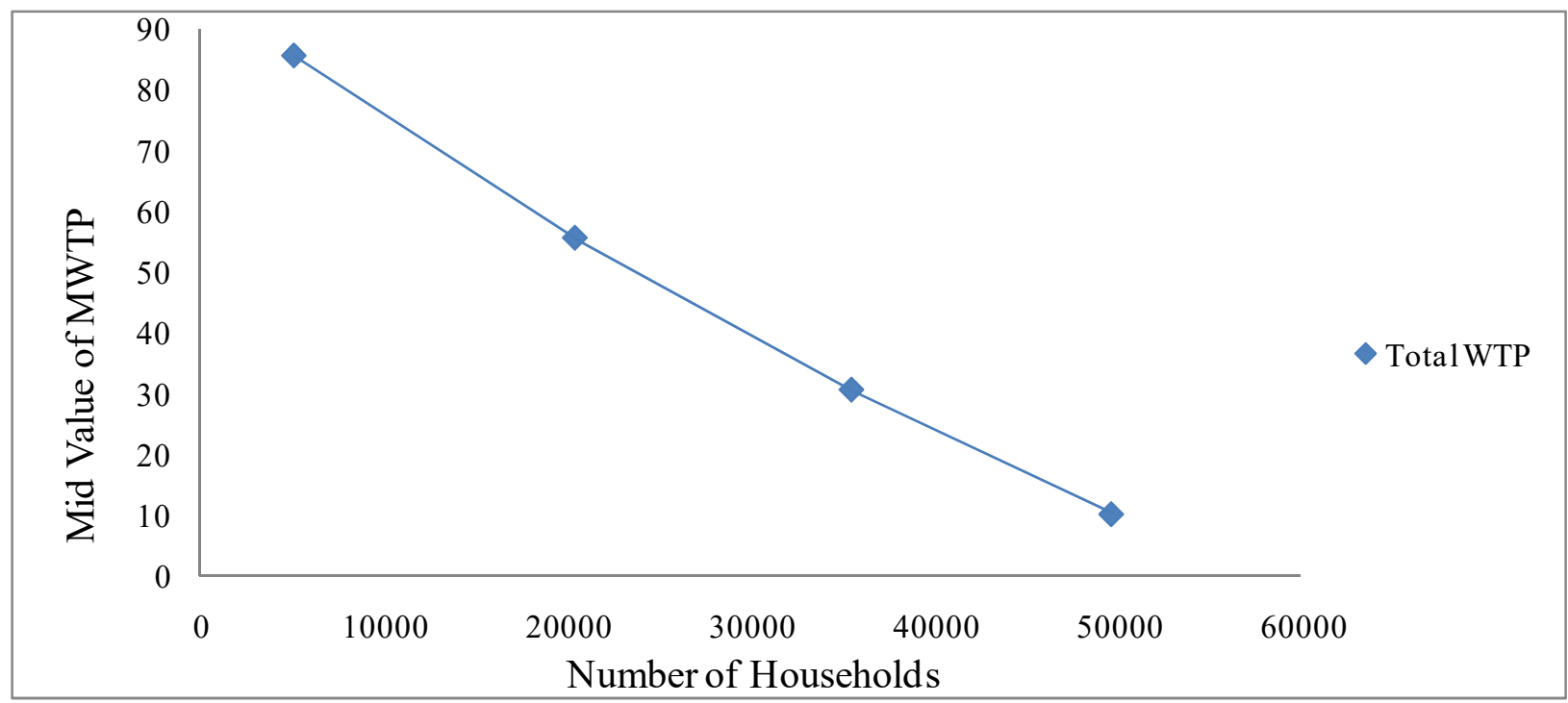

Source: Own Survey 2017

As seen from the above figure the number of households decline as the bid value (price) of improved water increases.

In general we found that the mean willingness to pay of households of Burayu town for improved water services is between 31.5 cents to 42.7 cents per one Jeri can of 20 liters from closed and opened ended formats respectively. Therefore the mean willingness to pay of households fails in the range of 31.5 and 42.9 cents per 20 liters of Jeri can. This amount is by far higher than what the town's improved water supply and sewerage enterprise is charging which is around 12.1 cents per 20 liters Jeri can for those households in average.

\section{CONCLUSION ANDPOLICY RECOMMENDATIONS}

\subsection{Conclusion}

The current improved water problem of the Burayu town is the source of idea for this study. Currently the fast growing of town's population and low cost recovery of the existing water service created a serious problem facing residents of the town. The amount of water produced per day and the daily requirement of improved water is unbalanced. The per capita consumption of improved water consumption is about 11.9litres which is by far below the standard of WHO 25litres. The households are suffering a lot from improved water shortage problems such as paying high prices for water vendors, using unsafe water obtained from non-piped sources and wasting their productive time to collect water from distant sources. The town's water supply and sewerage enterprise couldn't generate sufficient amount of funds to expand water projects which meet the growing demand.

Valuation of economic goods is important to allocate efficiently and enhance the welfare of society. Therefore, this study is mainly addresses the above problems and tries to reveal how much households of the town value the improved water services. Thus willingness to pay using contingent valuation method is the appropriate technique to study these type problems depending on the stated preferences of people for the given environmental good or services. This method is appropriate method because the good to be valued has no price in actual market as other consumer goods and therefore we create hypothetical market in which peoples can state their preferences for the good.

To identify determinants of willingness to pay for improved water econometrics models such as probit and tobit models were used. Some influential variables were included in the models depending on their theoretical relevancies and empirical significances. About 15 dependent variables were included in the analyses. Those variables can be categorized as households' characteristics such as gender, marital status, age, income, occupation status, family size and improved water attributes like source, quality, quantity and level of satisfaction. About four different bid values for improved water were randomly distributed for respondents. These bid values were selected during questionnaire pretest conducted for two days with 30 randomly interviewed respondents using open ended formats of how much the maximum amount they can pay for one Jeri can of improved water. Accordingly, 20, 30, 40 and 50 cents per 20 liters of container were chosen depending on the most frequently happed values (mode).

Of 239 sampled households, 22 questionnaires were dropped from analysis because of inconsistencies of responses and incomplete questionnaire. Thus, 217 useful responses were considered for analysis purposes. From 217 sampled households 197(90.78\%) use piped water and 20(9.22\%) non-piped (such as wells 16(80\%) 
and $4(20 \%)$ springs).Respondents asked whether the quantity of water they get per their respective shift is sufficient or not. About 165(76.04\%) respondents perceived that the quantity of current water delivered is low/ insufficient with low pressure. Only $52(23.96 \%)$ of respondents replied that the quantity of water they are getting is good. Regarding to the quality of water $113(52.07 \%)$ respondents said the water is poor and $104(47.93 \%)$ replied that it is clean. The surveyed households in average get improved water provision 6 days within a month with the minimum of 1 day and maximum 30 days. Of 171 who use private pipe $86.05 \%$, fetch water $1-15$ days per month and $13.95 \%$ fetch $16-30$ days per month. Households' average monthly water expenditure is 26.5 birr which is $0.67 \%$ of their mean monthly income. This shows that there is high potential to pay for improved water services in the town. The daily improved water consumption of households is in average about 2.86 Jeri can (i.e. 57.2 liters). Among 217 respondents only 69(31.80\%) own water tanker to cope up with water shortage and $148(68.20 \%)$ have no water tanker.

Respondents are asked to state whether they are satisfied with the current improved water services provided by the town's water and sewerage enterprise, and out of 217 respondents $172(79.26 \%)$ are not satisfied and only $45(20.74 \%)$ said they are satisfied. When they are asked to state their reason of dissatisfaction to the existing improved water provision services $170(89 \%)$ of respondents stated that the quantity and low pressure are the main causes. The rest $47(11 \%)$ respondents explained the quality water obtained from the source is the main causes of their dissatisfaction. Of 26 surveyed households using public fountains revealed that they waste about 2 hours in average to bring water back to their home per day from this source. Of 20 households, using nonpiped water their primary concern is the quality of the water.

From 217 respondents 160(73.73) replied "yes" and 57(26.67\%) respondents said "no" to the bid value of improved water services.

Households characteristics' such age, income, occupation and education are positively determine the probability of accepting the given bid value of improved water. The bid value, quality, source of water and quantity variables negatively affect the probability of accepting bid value of improved water in probit model. Those variables affecting the likely of willingness to pay positively also have fortunately the same sign in tobit model of determining the maximum willingness to pay. From the result of this study, we concluded that the mean willingness to pay for one Jeri can of improved water was 31.5 cents and 42.7 cents in closed ended and open-ended formats respectively. Thus, the households' mean willingness to pay for improved water is between the interval of 31.5 and 42.7 cents for 20 liters of improved water. This result is by far more than the current tariff structure of the town's water supply and sewerage enterprise which is about 9 cents per 20 liters container in the block of $0-3 \mathrm{~m}^{3}, 4-5 \mathrm{~m} 311$ cents, $6-8 \mathrm{~m} 312$ cents, $9-11 \mathrm{~m} 313.5$ cents and $>12 \mathrm{~m} 315$ cents.

The aggregate willingness to pay of households was also estimated to be 1881052 cents for one Jeri can of 20 liters. The aggregate willingness to pay households per month is estimated to 1.6 million birr. Therefore, if the improvement scenario can be effected it not only solves the shortage of improved water problems but also the town's water supply and sewerage enterprise can increase it revenue and able to sustain the growing improved water demand.

\subsection{Recommendations}

This section deals with some policy recommendations derived from the results of the study findings.

This study reveals households are not satisfied with the current water supply services due to low quantity, poor quality and low coverage. Households are willing to pay more than the current tariff if the improvement programs are conducted. Therefore, the town's water supply and sewerage enterprise should undertake the construction of additional boreholes to meet the daily per capita consumption standards.

Most of the time urban utility providers look into the supply side of the service, which is often constrained by financial resources. However, we recommend the problem require intensive demand side study in order to arrange cost recovery strategies in urban utility provisions.

The current tariff structure policy should base on the willingness to pay and affordability of residents. The result shows that as income level of households' increases the probability of paying for improvement scenario also increases. This implies that cross subsidization strategy is appropriate since higher income group can subsidize the lower income through progressive tariff structure.

The water supply and sewerage enterprise should also increase the current households' private pipe connections as improve services and collect sufficient revenue.

Occupation status and income have positive and significant effect on households' willingness to pay for improved water, thus the town's administration should focus on job creation activities especially for youth section of society. Since educated section are more willing to pay than uneducated one, the concerning body should work hard in promoting adult education in particular.

\section{Reference}

Ajzen, I., et al (1996). Information Bias in Contingent Valuation: Effects of Personal Relevance, Quality of 
Information, and Motivational Orientation. Journal of Environmental Economics and Management, 30, 4357.

Alebel Bayru (2004). Analyses of Affordability and Willingness to Pay for Improved Water Supply in Urban Areas of Ethiopia: Strategy for Full Cost Recovery.Msc thesis.Addis Ababa University. Addis Ababa, Ethiopia.

Alemu, M. (2000). "Valuation of Community Forestry in Ethiopia: A Contingent Valuation Study of Rural Households". Environment and Development Economics. 5 (2000): 289-308.

Altaf, M.A. and Hughes, J.A. (1994). Measuring the demand for improved urban sanitation services: Results of a contingent valuation study in Ouagadougou, Burkina Faso, Urban Studies, 31(4), 509-551.

Arrow, K., et al.(1993) "Report of the NOAA Panel on Contingent Valuation,” Federal Register, 58 (10): 4601 14

Ayanshola, A.M., Sule, B.F. and Salami, A.W. Evaluation of willingness to pay for reliable and sustainable household water use in Ilorin, Nigeria, Ethiopian Journal of Environmental Studies and Management Vol. 6 Supplement 2013.

Bamlaku, A. et al. (2015). Smallholder Farmer's Willingness to Pay for Improved Soil and Water Conservation Practice: A Contingent Valuation Study in Abaro - Toga Watershed Ethiopia. American Journal of Business, Economics and Management. Vol. 3, No. 6, 2015, pp. 432-441.

Beaumais,O.(2014).What are households Willing to pay for Better tap water Quality?: A cross-country Valuation study, Fondazione Eni Enrico Mattei Working Paper Series, France.

Bogale, A and Urgessa (2012). Households' Willingness to Pay for Improved Rural Water Service Provision: Application of Contingent Valuation Method in Eastern Ethiopia, African Centre for Food Security, University of KwaZulu-Natal, South Africa.

C.R .Kothari (2009). Research Methodology: Methods and Technique. $2^{\text {nd }}$ ed. New Age International (P) Ltd., Publishers. India

Cameron, T.A. and D.D. Huppert. (1988). OLS versus ML estimation of non-market resource values with payment card interval data. Journal of Environmental Economics and Management, 17: 230-246.

Carl, M. (1985). Investigations into the Method of the Social Sciences with Special Reference to Economics, ed. By Louis Schneider, New York University Press, New York.

Carson R. (2000)."Contingent Valuation: A Users Guide", University of California, Department of Economics, San Diago, California.

Ciriacy-Wantrup, S.V. (1947). "Capital returns from soil-conservation practices". Journal of Farm Economics 29, 1181-1196.

Donaldson, C., Thomas, R., \& Torgerson, D. J. (1997).Validity of open-ended and payment scale approaches to eliciting willingness to pay. Applied Economics, 29, 79-84.

Dutta,B.(2003).The Scope and Structure of Welfare Economics, University of UK.

Edward,W. (1966), Limitations of Travel-cost Techniques: Implications for Outdoor Recreation Policy, MA, University of British Colombia, USA.

FAO(2003). Review of world water resource by country. Water report, 23. Rome: Food and Agriculture Organization of the United Nations; Free downloads from IFPRI.

FAO, Corporate Documents Repository: Application of Contingent Valuation Method in Developing Countries PDF notes: $h t t p: / / w w w / f a o$ org /decrep/003/x8955e03.htm.

Fauzi, Akhmad (2004). "Analyzing demand for improved water services". Jakarta: Indonesia.

Fekadu Megersa(2011). Assessing Households Willingness to Pay For Improved Water Supply Services in Holeta Town Using Contingent Valuation Method, MA In Water Resources Planning and Management, Addis Ababa University.

Frank, A. (2006). Environmental and Natural Resource Economics, $4^{\text {th }}$ Edition, New State Mexico University, USA.

Freeman, A.M. (1993). The Measurement of Environmental and Resource Values: Resource for the future, Washington D.C. USA.

Friedman, D.(1990).Price Theory: An Intermediate Text, Western Publishing Co.

G. Howard and J. Bartram(2004) Water, Sanitation and Health Program, World Health Organization, Geneva, Switzerland

George, Henry (1962). The Science of Political Economy, New York, Robert Schulenburg Foundation, USA.

Green .W.H. (2011), Econometric Analysis, $4^{\text {th }}$ ed.New York, Macmillan Publishing Company.

Haab, T.C. and K. E McConnell (2002). Valuing Environmental and Natural Resources: The Economics of NonMarket Valuation, New Horizon in Environmental Economics, Printed and Bounded in Great Britain by MPG books Ltd, Bondman, and Cornwall.

Hahnemann, W.M., Loomis, J., and Kanninen, B., (1991). Statistical Efficiency of Double Bounded Dichotomous Choice Contingent Valuation. American Journal of Agricultural. Economics 73 (4): 1255 - 
1263.

Hanemann, W.M. (1991). Willingness to pay and Willingness to Accept: How much can they differ? American Economic Review.

Hanley, N.F.et.al (1997).’Environmental Economics in Theory and Practice”. Macmillan Press Limited, London.

Hanley,N, Shogren,J and White, B ( 2001). Introduction to Environmental Economics. $1^{\text {st }}$ edition, Oxford University Press.

Hoehn, J and A. Randall (1987). "A satisfactory Benefit and Cost Indicate from Contingent Valuation": Journal of Economics and Management .Vol.14 No.3:226-247.

Hoyos, D. (2010). "The State of the Art of Environmental Valuation with Discrete Choice Experiments." Ecological Economics, Vol. 69, pp. 2372-2381.

Hussein, A. (2004). Principles of Environmental Economics. $2^{\text {nd }}$ ed.Routledge.USA.

Jeanty, P. et al.(2007). Selected paper prepared for presentation at the American Agricultural Economics Association Annual Meeting, Portland, Oregon.

Johnston (2002).Economic Methods, $4^{\text {th }}$.ed. McGraw-Hill Companies.

Kadisa, K. (2013). Willingness to pay for improved water supply services in Phaleng ward, Shoshong, Botswana: Application of Contingent Valuation Method (CVM), MSc in Integrated Water Resources Management, University of Zimbabwe, Faculty of Engineering.

Medhin Fisseha (2006). "Households demand for improved water supply services Addis Ababa town using contingent valuation method", M.Sc. thesis, Department of Economics, Addis Ababa University.

Merger, C. (1976).Principle of Economics. Institute for Humane Studies, New York

Mezgebo Gidey and Ewnetu (2015). Households Willingness to pay for improved water services, Neblet town, Ethiopia, Journal of Development and Agricultural Economics, Vol.7 (1),pp.(12-19).

Mitchell, R.C. and R.T. Carson (1995). 'Current Issues in the Design, Administration, and Analysis of Contingent Valuation Surveys', in P. Johansson, B. Kriström and K. Mäler, eds., Current Issues in Environmental Economics. Manchester: Manchester University Press.

Mitchell, R.C. and R.T.Carson, (1989). Using Survey to Value Public Goods. The Contingent Valuation Method, Resource for the Future, Washington DC.

Mvangeli, N.(2015). Households' Water use demand and willingness to pay for improved water services: A case study of semi-urban areas in the Lubombo and Lowveld regions of Swaziland, Msc in Agricultural and Applied Economics, Lilongwe University of Agriculture and Natural Resources, Swaziland.

Nations Human Settlements Programme (UN-HABITAT), World Health Organization (WHO). (The) Right to Water, Fact Sheet No. 35. 2010

Pearce, D. (2001)."Valuing Environmental diversity": Issues and Overview, OECD, Valuation of biodiversity benefits: Selected Studies, OECD. Paris.

Perman, R, Ma, Y, Mc Glary and Common (2011)."Natural Resource and Environmental Economics, 4th edition, Person Education Limited, Printed and Bounded by Bell and Bain Ltd.

Press, Tucson. Willis, Ken. (1995). "Contingent Valuation in a Policy Context: The National Oceanic and Atmospheric Administration Report and Its Implications for the Use of Contingent Valuation Methods in Policy Analysis in Britain.” in Environmental Valuation: New Perspectives, ed K.G.Willis; Corkindale, J.T. The University of Arizona.

Randall, Alan, Berry C. Ives, and Clyde Eastman (1974), "Bidding Games for Valuation of Aesthetic Environmental Improvements." Journal of Environmental Economics and Management (1974): 132-149.

Solomon Tarfasa (2013). How much are households willing to contribute to the cost recovery of drinking water supply? Results from a household survey. Published: 24 April 2013, Journal of Water Engineering Science, 6, 33-38, 2013.

Tamirat Minota (2014). Determinants of Households' Willingness to Pay for Improved Water supply services in Dilla town, Southern Ethiopia: An application of Contingent Valuation Method, Msc thesis, Addis Ababa University, Addis Ababa.

UNDESA (2014). International Decade for Action," Water for Life", 2005-2015.

UNESCO (2016). World Water Development Report.

UN-GLAAS (2017).Financing universal water, sanitation and hygiene under the sustainable development goals Global Analysis and Assessment of Sanitation and Drinking-Water, Geneva.

UNICEF (2008), Water Sanitation and Hygiene Report. New York.

United Nations, Office of the High Commissioner for Human Rights (OHCHR), United

University Press.

USAID (1998). Guidelines for conducting willingness to pay for developing countries. Bureau of Science and Technology: USA, Washington DC.

Varian,H.(1992). Microeconomics Analysis. $3^{\text {rd }}$ eds. Norton \& Company,New York

Verbeek M. (2004).A Guide to Modern Econometrics.2 ${ }^{\text {nd }}$.ed.John Wiley and Sons Ltd., England. 
Verbeex, M. (2012) A Guide to Modern Econometrics.4 $4^{\text {th }}$ ed. Rotterdam school of management, Erasmus University, Rotterdam.

WHO (2003).Domestic water quantity service report, Geneva, Switzerland.

William, S. (1931). An Introduction to Theory of Value, McMillan and Co. Limited, S.t. Martins Street, London.

Wright, S.(2012).Using CV to Estimate Willingness to Pay for Improved Water Source in Rural Uganda, Msc thesis, Michigan Technology University.

Yibeltal, B.,(2011), The value of improved water supply service in Motta town, East Gojjam, Ethiopia: Application of contingent valuation method (CVM), Addis Ababa University, School of Economics Addis Ababa.

Zuhair, A. (1995). Measurement of Welfare Change, A review, Iowa State University, USA. 